\title{
BMJ Global Health Effects of expanding a non-contributory health insurance scheme on out-of- pocket healthcare spending by the poor in Turkey
}

Abdullah Tirgil, ${ }^{\oplus 1}$ William T Dickens, ${ }^{2}$ Rifat Atun ${ }^{\oplus 3}$

To cite: Tirgil A, Dickens WT, Atun R. Effects of expanding a non-contributory health insurance scheme on out-of-pocket healthcare spending by the poor in Turkey. BMJ Global Health 2019;4:e001540. doi:10.1136/ bmjgh-2019-001540

Handling editor Valery Ridde

- Additional material is published online only. To view please visit the journal online (http://dx.doi.org/10.1136/ bmjgh-2019-001540).

Received 28 February 2019 Revised 4 July 2019

Accepted 5 July 2019

(D) Check for updates

(C) Author(s) (or their employer(s)) 2019. Re-use permitted under CC BY-NC. No commercial re-use. See rights and permissions. Published by BMJ.

${ }^{1}$ Department of Public Finance, Faculty of Political Sciences, Ankara Yildirim Beyazit University, Ankara, Turkey ${ }^{2}$ Department of Economics, College of Social Sciences and Humanities, Northeastern University, Boston,

Massachusetts, USA

${ }^{3}$ Harvard T.H. School of Public Health, Harvard University, Boston, Massachusetts, USA

Correspondence to

Dr Rifat Atun;

ratun@hsph.harvard.edu

\section{ABSTRACT}

Introduction Insufficient or no health insurance creates financial access barriers to healthcare services, especially for vulnerable populations. The Green Card scheme, a noncontributory government-funded health insurance scheme for the poor in Turkey, was expanded in 2003-2006 and has provided citizens with extended benefits. We study the effects of this expansion of the Green Card scheme on out-of-pocket healthcare expenditures for low-income households.

Methods We use difference-in-differences study design to examine the causal impact of having a Green Card on financial protection in terms of out-of-pocket health expenditures and catastrophic expenditures for the poor in Turkey. In addition, we implement quantile regression analysis to examine how the benefits expansion affects the poor who have the largest out-of-pocket expenditures and are in the upper tail of the health spending distribution.

Results We find that the expansion of benefits coverage leads to significant reductions in annualised out-of-pocket healthcare expenditures for dental care, diagnostics services, pharmaceuticals and total medical spending. We show that the decline in spending by Green Card beneficiaries corresponds to about $33 \%$ as per cent of total per-household medical spending. Quantile regression analysis shows that the scheme is even more effective at reducing expenditures for those people facing large health expenditures. The scheme reduces the incidence of catastrophic expenditures by nearly $50 \%$ among those with the largest annual out-of-pocket expenditures. Conclusions Increasing benefits coverage for a noncontributory insurance programme leads to financial protection for the poor by reducing out-of-pocket and catastrophic health expenditures. It is even more effective at reducing out-of-pocket health spending for those whose health expenditures that lie on the high end of healthcare spending distribution.

\section{INTRODUCTION}

Out-of-pocket spending for healthcare services can place a great financial burden on those with limited resources, thereby preventing them from accessing the care they need and increase inequity among citizens. ${ }^{1-3}$

\section{Key questions}

\section{What is already known?}

- Poor households with no or insufficient health insurance coverage incur high levels of out-ofpocket health expenditures and often experience catastrophic health expenditures when receiving necessary healthcare services they need.

- Expanded health insurance coverage aims to address these expenditures, which are a major barrier to accessing healthcare services.

\section{What are the new findings?}

- Using difference-in-differences study design, we find that expanded insurance coverage helped protect the poor against the cost of illness in a developing country, which corresponds to a $33 \%$ decline in their medical spending.

- Further, our quantile regression results show that the Green Card scheme programme is progressive in that it has helped to more significantly reduce outof-pocket and catastrophic health expenditures for those who are in the upper tail of the health spending distribution, and thereby enhancing equity in healthcare financing.

\section{What do the new findings imply?}

- This study demonstrates that non-contributory schemes can effectively enable low-income groups to access healthcare services with financial protection.

- This is especially true for those in the upper tail of health spending distribution-a group at high risk for high out-of-pocket and catastrophic health expenditures without any or adequate insurance coverage, who may lose their assets and savings to get the necessary treatment or just forgo healthcare.

Health insurance (if offered fully and fairly) reduces financial risk. ${ }^{4-9}$ However, it may also increase health expenditures and costs. ${ }^{10-15}$ Patients may demand more care as the price of a health service decreases if demand for care is elastic. ${ }^{16}$ In addition, increased demand for 
healthcare services can cause prices to rise if the supply of care is less than perfectly elastic.

In 2003, Turkey began a multiyear health system reform to introduce universal health coverage (UHC). The reforms were introduced to overcome major inequities in health outcomes, expand access to health services and provide financial risk protection for all citizens especially the poor who were not covered by any social security programmes and faced high financial risk from health expenditures. ${ }^{17}$

Prior to health system reforms that began in 2003, high out-of-pocket expenses were a problem in Turkey. According to the National Health Accounts study in 2002-2003, 30\% of total health spending was composed of out-of-pocket payments. ${ }^{18}$ High out-of-pocket payments is a major reason why individuals may delay access to healthcare, interrupt ongoing treatment or not seek treatment at all. Prior to the reforms, $93.3 \%$ of the beneficiaries of the non-contributory insurance scheme for the poor in Turkey stated that they abandoned their treatment due to financial constraints. ${ }^{19}$

Prior to the health system reforms, Turkey had a fragmented health insurance system which consisted of five different health insurance schemes, each with a different benefits package: Social Insurance Organization for formal sector employees, Government Employees Retirement Fund for retired civil servants, Active Civil Servants Insurance Fund for civil servants in work and their dependents, Bağ-Kur for artisans, self-employed and agricultural workers and Green Card insurance scheme for the poor. ${ }^{20}{ }^{21}$ This variation in benefit produced inequities among beneficiaries of different health insurance schemes when accessing care and for out-of-pocket health expenditures. ${ }^{17}$

When the Green Card scheme was first introduced in 1992, it covered a limited number of services, such as inpatient treatment costs for the enrollees and consequently take-up rates were low. ${ }^{21}$ In 2003, prior to the reforms, only 2.3 million people (around $20 \%$ of those eligible) were registered under the Green Card scheme. In December 2004, the coverage was expanded to include costs of outpatient doctor visits, some dentist visits and diagnostics services at Ministry of Health $(\mathrm{MoH})$ hospitals and university hospitals. Starting in January 2005, the benefits further expanded to include outpatient prescription drugs. The expansion in coverage of benefits resulted in increased participation in the Green Card scheme. By 2006, 8.3 million people were registered, and by 2011, when the Green Card scheme benefits package became comparable to other types of insurance, the number of enrollees increased to 9.1 million. $^{21}$

As a non-contributory scheme, the Ministry of Finance transferred necessary funds to $\mathrm{MoH}$ to pay healthcare service providers for the utilisation of healthcare services by Green Card enrollees. Enrolment to Green Card scheme was voluntary. If a person is qualified for the card, then she would receive her own green booklet to show at the health facility to identify herself as a green card beneficiary. Furthermore, to target the poor Green Card eligibility was restricted to households according to a threshold set by the government where 'total household income divided by the number of household members was less than one-third of the minimum wage'. ${ }^{21} 22$

Earlier published studies have described aspects of the Turkish health insurance system, ${ }^{23} 24$ and several international studies have examined the effects of insurance on out-of-pocket medical spending in other countries. ${ }^{5} 710$ However, to date, no studies of the Green Card expansion in Turkey have used techniques to plausibly establish a causal relation between changes in the insurance system and health system outcomes related to utilisation and financial protection. Aran and Hentschel, who examined the impact of Green Card on out-of-pocket expenditures, argued that Green Card offered limited financial protection. ${ }^{22}$ However, their conclusion was based on a comparison of the expenditures of Green Card holders with those with no insurance after the policy change. However, as there was no comparison of the differences between the two groups before the change, it was not possible to ascertain if the difference predated the expansion. Yardim et al examined the level of catastrophic health expenditure in Turkey to claim that people on average were better protected from catastrophic health expenditures by $2006 .{ }^{25}$ However, they based their conclusions on comparison of data from three points in time and hence could not deduce whether what they were observing was due to increasing incomes as opposed to the changes in the health insurance system. We use difference-in-differences design in our study to examine the effect of the 2005 coverage expansion of the Green Card scheme and to address these methodological issues identified in the earlier published studies to demonstrate plausibly the effect of health insurance on utilisation and out-ofpocket expenditures for the Green Card beneficiaries.

Health expenditures tend to be concentrated among those with health problems. Hence, in addition, we examine the impact of the change in the Green Card programme on people at different points in the expenditure distribution-an important and original contribution.

\section{METHODS}

We use difference-in-differences study design to estimate the impact of health insurance reforms on out-of-pocket health expenditures for the poor. By comparing the changes in health expenditures of Green Card holders to others who were not affected by the change, we can separate out the impact of a common trend affecting the two groups and examine the relative change in the affected group, namely the Green Card beneficiaries. We compare the expenditures of Green Card holders in 2003 and 2004 before the Green Card expansion and in 2005 and 2006 after the expansion happened to that of holders of other types of insurances. We chose these years that coincide with the Green Card expansion to examine 
its effect and to avoid contamination by other elements of the health reforms which were introduced subsequently in later years.

We use quantile regression and analysis of the frequency of catastrophic levels of health expenditures to document the impact of the Green Card expansion on large expenditures. To our knowledge, no previous study of insurance schemes have used such methods to study the impact of health insurance on the distribution of healthcare expenditures for low-income households.

We use Turkey Household Budget Surveys (THBS) between 2003 and 2006 undertaken by the Turkish Statistical Institute (TurkStat) allowing us to observe expenditures before and after the Green Card expansion. These data contain information on household-level healthcare expenditures for 25920 households in 2003; 8600 households in 2004 and 8640 households in 2005 and $2006 .{ }^{26}$

The THBS data include healthcare spending by type of expenditures, such as physician, diagnostics, dental, pharmaceutical, inpatient and so on and by the source of payment such as out-of-pocket expenditures. We construct total household out-of-pocket medical spending as the sum of expenditures in all categories. People with out-ofpocket outpatient healthcare expenditures (doctor visits, diagnostics and dental care) consist of $12 \%$ of the total sample, while the people with out-of-pocket pharmaceutical spending is $39 \%$ of the sample.

The THBS are nationally representative and are repeated cross sections. They also contain a wide range of demographic and household characteristic variables including household head $(\mathrm{HH})$ marital status, $\mathrm{HH}$ gender, $\mathrm{HH}$ age, household location, household size, $\mathrm{HH}$ occupation and insurance status of household members. For our analysis, we create some variables such as fraction of children, fraction of elderly and fraction of females in each household.

The data were collected at household level. Out-ofpocket health expenditures were recorded as actual monthly spending (Turkish Lira (TL)) in each dataset. We transform these monthly spending into annualised health expenditures and use them in our analysis. All expenses are converted to 2003 prices using the Consumer Price Index from TurkStat.

Online supplementary appendix table 1A presents the descriptive statistics for our sample broken down by insurance groups. We report the mean female $\mathrm{HH}$, fraction of children in household, fraction of elderly in household, urban, fraction female in household, household size, $\mathrm{HH}$ age, $\mathrm{HH}$ married before and after the coverage expansion occurred (ie, 2003-2004 vs 2005-2006). We choose to include these control variables in the statistical analysis as they are more likely to affect household out-of-pocket health expenditures. For example, fraction of children and elderly in households can cause higher health expenditures as they typically use health services more frequently.

Most of the time, the means are similar though not identical. The comparison group (social insurance) experiences about $12 \%$ point increase in urban, which is the opposite in the treatment group (Green Card) such that we see a $9 \%$ point decline in this group. Fraction of elderly in household in the treatment group goes down about $2 \%$ point after the expansion in 2005 , but we do not see any change in the comparison groups percentage elderly. The rest of the variables do not show any significant change in their composition before and after the change. Inclusion of these variables as controls in the statistical analysis does not substantively affect the results.

As we use cross sections of the population at different points in time means we are not following the same people. While stable populations would be preferable, it is common to use difference-in-differences on synthetic cohorts or groups defined by treatment status and doing so does not necessarily invalidate the method. ${ }^{27}$ However, a problem can arise in these cases if people are self-selecting into the treatment group. Increasing urban population with social insurance and decreasing Green Card beneficiaries after the reform may overestimate our results (online supplementary appendix table 1A). We acknowledge this problem but believe that if anything it leads us to underestimate the reduction in expenses green cards cause.

First, consider who is likely to select into an insurance scheme when benefits increase. Most likely these would be people who would anticipate substantial savings from doing so-that is, people anticipating significant medical expenses in the newly covered categories. Having such people join the treatment group would bias estimates of savings from the Green Card scheme downward. One might also be concerned that the drop in the fraction of Green Card holders and the increase in those with Social Insurance might bias our results. They may, but again we think this may bias our estimates of reductions in expenses downwards. To move from Green Card to Social Insurance, one would most likely have to obtain a job, and healthy people with money to spend on medical care would be the ones most likely to leave the Green Card group. Finally, the Green Card group having a larger representation of rural residents might be troubling, especially if the rural participants had lower average expenditures than urban participants. Surprisingly, this is not the case. In our sample before and after the increase in Green Card benefits, rural household had larger out-of-pocket expenses on average than urban households.

The survey samples all settlements in the territory of the Republic of Turkey. Institutional populations (soldiers, individuals living in dormitories, prisons, longterm hospital residents, homes for the elderly, etc) are excluded from the survey. We include in panel 1 our identification strategy and estimating equations.

\section{Patient and public involvement}

It was not appropriate or possible to involve patients or the public in this work as we used publicly available data. 
Our main interest is whether Green Card holders are protected from out-of-pocket healthcare expenditures with respect to doctor visits, dental care, diagnostic services, pharmaceutical expenses and total household medical spending which includes all types of healthcare expenses. We compare those who report having Green Card insurance (the treated sample) with those who have other types of insurance (the comparison sample) at the time of the survey.

The comparison group includes those with social insurance (includes Sosyal Sigortalar Kurumufor formal sector employees, Bağ-Kur for selfemployed and artisans, Emekli Sandığı for retired civil employees), private insurance and uninsured who report not having any form of insurance. Those with these insurances are a good comparison group because there was no shift in their insurance coverage at the time of the policy change.

As our main analysis, Eq. (1) would compare those who have a Green Card with those who are considered to fall within one of these comparison groups: social insurance, private insurance or other insurance and uninsured. All groups were combined into one comparison group. For all outcomes of interest, we use the years from 2003 through 2006, 2005 being the cut-off so that we observe equal numbers of periods before and after the change.

The advantage of difference-in-differences estimation over a before-and-after comparison is that it controls for trends affecting not only those in the treatment group but also the population in general. ${ }^{28}$ Its advantage over a postchange comparison of those treated and those not treated is that it allows for initial differences in the two groups. The difference-in-differences technique improves on both of these alternatives by controlling both for initial differences between the two groups as well as changes before and after due to a common trend.

The double-difference estimate of benefits expansion in insurance coverage is estimated by Eq. (1):

$$
\begin{aligned}
Y_{i g t}= & \beta_{0}+\beta_{1} .\left(\text { Green } \text { Card }_{i g t} * \text { Post }_{\text {Time }}\right) \\
& +A_{t}+G_{g}+\text { B. } X_{i g t}+e_{i g t}
\end{aligned}
$$

In this difference-in-differences framework, $i$ denotes household, $t$ denotes month (2003-2006) and $g$ denotes insurance groups (eg, social insurance, private insurance, Green Card and uninsured). $Y_{i g t}$ is the out-of-pocket healthcare expenditures in the last month. Green Card igt is a binary variable indicating whether household $i$ has a Green Card at time $t$. Post Time $e_{t}$ is an indicator for years after the coverage expansion. The coefficient of interest is $\beta_{1}$, which would capture the impact of the Green Card insurance and multiplies the interaction term, Green Card igt $^{*}$ Post Time $_{t} . \mathrm{A}_{t}$ is a year fixed effect, $G_{g}$ is an insurance type fixed effect take a unique for each other type of insurance, $X_{i g t}$ is a vector of household characteristics with $\mathrm{B}$ a conforming vector of coefficients. $\beta_{0}$ is the constant term and $\mathrm{e}_{\text {igt }}$ is the error term which represents all things affecting $Y_{\text {igt }}$ that are not specifically accounted for in the equation.

The key identifying assumption in difference-in-differences models is that changes in the values of the dependent variable for both the treated individuals and the comparison group would be the same in the absence of treatment. ${ }^{29}$ This is referred to as the 'parallel trends' assumption. We test this assumption in all types of health expenditures for the treated and comparison groups in the 2 years before the change (2003 and 2004$)$. If the two groups had separate trends we would expect the coefficients on the interaction of year and Green Card to be large and statistically significant. In no case, do we reject the null hypothesis of common trends (online supplementary appendix table $2 \mathrm{~A}$ ).

We implement difference-in-differences method using ordinary least squares to identify the causal impact of having a Green Card on financial protection in terms of out-of-pocket health expenditures for the poor in Turkey. The sample includes all households, including those with zero healthcare expenditures, as well as those with positive expenditures. We account for all these differences by estimating Eq. (1) with a set of controls for demographic and socioeconomic characteristics. We control for year fixed effects as well as some predetermined household variables such as HH marital status, HH gender, fraction of kids, fraction of elderly, fraction of female in the household, household geographic location such as urban or rural, household size, $\mathrm{HH}$ age, $\mathrm{HH}$ age squared and $\mathrm{HH}$ occupation.

Cade and Noon point out that responses to driver variables can differ significantly at different points in the distribution of outcomes and recommend the use of quantile regression to explore how responses differ. ${ }^{30} \mathrm{To}_{\mathrm{get}}$ at the impact of the law on those with expenditures in the upper tail of the expenditure distribution, we use this technique. Changes at these higher ends of the expenditure distribution are notably larger than the average change. As a sensitivity analysis, to control whether this result is affected by any outliers, we exclude households who make monthly expenditures of at least $2000 \mathrm{TL}$ from the sample and rerun the quantile regressions.

What this technique does is to calculate the impact of the policy change not on the mean put on households at a particular percentile of the distribution. For example, in one analysis we look at those at the 90th percentile of the expenditure distribution. See Cade and Noon for a thorough discussion of the use of quantile regression. ${ }^{30}$

It is possible that the impact of the Green Card expansion would be different in urban and rural areas due to differences in the availability of healthcare. We run separate analysis for urban and rural dwellers to examine this possibility.

Households without full insurance can face expenditures which cause a severe disruption to their living standards. We define categories of catastrophic health expenses and use difference-in-differences to examine the impact of the Green Card expansion on the frequency of such events. Following previous studies, we define catastrophic expenses as those that exceed $15 \%, 25 \%$ and $40 \%$ of non-food expenditures. ${ }^{31-34}$

Let $\mathrm{k}$ be out-of-pocket healthcare expenditures, $\mathrm{x}$ be total household expenditures and $\mathrm{f}$ be food expenditures. Then, a household is said to have faced catastrophic spending if $k / x$ or $k /(x-f)$ pass a certain threshold, $z$. Define $E$ being equal 1 if $[k /(x-f)]>z$ and 0 otherwise. ${ }^{34}$ Then, we run the regression of $E$ focusing on the interaction term between the Green Card and the time variables. We use robust SEs to account for the heteroskedasticity introduced by having a dichotomous-dependent variable.

\section{RESULTS}

\section{Impact estimates of benefits expansion}

Difference-in-differences estimates of the impact of the benefits expansion in insurance coverage with and without X variables are presented in table 1 . All point estimates of the impact of the Green Card change on out-ofpocket expenditures are negative. Most are statistically significant including the effects on total expenditures 
Table 1 Difference-in-differences estimates of the impact of benefits expansion in insurance coverage for Green Card on annualised out-of-pocket healthcare expenditures (full sample, in Turkish Lira)

\section{Treatment effect}

Outcome

(1)

(2)

\begin{tabular}{lcc}
\hline Doctor visit & $-5.316(5.868)$ & $-4.560(5.868)$ \\
\hline Dentist & $-11.496^{\star \star \star}(4.404)$ & $-9.408^{\star \star}(4.332)$ \\
\hline Diagnostic & $-8.592^{\star \star}(4.944)$ & $-7.152^{\star}(4.908)$ \\
\hline Household pharmaceutical medical spending & $-13.500^{\star \star}(6.756)$ & $-12.756^{\star \star}(6.816)$ \\
Household total medical expenditures & $-64.752^{\star \star *}(17.004)$ & 178.416 \\
Compare declines above with: & 33 \\
Mean total household medical spending & Yes \\
\hline Total decline as per cent of total per-household medical spending & 51425 \\
\hline X variables & No & $517.052)$ \\
\hline Observations & 51425 & \\
\hline
\end{tabular}

Authors' analysis of Turkey Household Budget Surveys: 2003, 2004, 2005 and 2006 . Robust SEs are in parentheses. ${ }^{*} 10 \%{ }^{* *} 5 \%$, ${ }^{* *} 1 \%$ in a one-tailed t-test. Difference-in-differences estimates are in Turkish Lira adjusted for inflation. Treatment subject is Green Card holders and comparison subjects are social insurance, uninsured (people reporting not having any form of insurance or Green Card coverage) and privately insured (includes other insurances). Results are based on Eq. (1) and are yearly. Demographic and socioeconomic controls include household head $(\mathrm{HH})$ marital status, $\mathrm{HH}$ gender, fraction of kids, fraction of elderly, fraction of female in the household, urban, $\mathrm{HH}$ size, $\mathrm{HH}$ age, $\mathrm{HH}$ age squared, $\mathrm{HH}$ occupation and dummies for insurance groups. We also control for year fixed effects in each model. Results are for 2003 through 2006; 2005 is the threshold.

which are significant at the $1 \%$ level in both specifications. Impacts on dental care, diagnostics, pharmaceutical and total expenditures are significant even when controls are included. We estimate that the expansion of Green Card coverage reduced out-of-pocket payments on household total medical spending by about 59.00 TL on average per year for Green Card beneficiaries. It is also worth mentioning that adding controls to the regression does not noticeably shift the estimates suggesting that the difference-in-differences strategy is doing a good job of controlling for omitted variables. The effect of the insurance coverage expansion corresponds to a $33 \%$ reduction of average yearly out-of-pocket total health spending for Green Card enrollees. Evidence suggests that married households spend more on total medical expenditures on average by about $60 \mathrm{TL}$ per year. We also control for age and quadratic age terms in the regression analyses to see the relationship between age and total household medical spending. The estimates show a U-pattern for this covariate suggesting with older HHs spending on health is greater compared with younger HHs. Another important result is that households with more female members spend more on health on average by about 48 TL per year.

Estimated effects on expenditures are negative and larger for a sample of households with positive expenses only. Results are not statistically significant (table 2),

Table 2 Difference-in-differences estimates of the impact of benefits expansion in insurance coverage for Green Card on annualised out-of-pocket healthcare expenditures (sample of households with positive spending, in Turkish Lira)

Treatment effect

Outcome

Doctor visit

Dentist

Diagnostic

Household pharmaceutical medical spending

Household total medical expenditures

Compare declines above with:

Mean total household medical spending

Total decline as per cent of total per-household medical spending

$X$ variables

No

(1)

$-9.660(66.120)$

$-177.900(251.484)$

-160.140 (332.448)

$-26.028^{*}(16.38)$

$-88.056^{\star \star \star}(37.296)$
Observations

(3)

(2)

$-8.496(65.700)$

$-138.696(260.676)$

4987

985

-169.704 (341.676)

1112

$-26.856^{\star}(16.428) \quad 20266$

$-82.260^{\star \star}(37.320)$

23245

Authors' analysis of Turkey Household Budget Surveys: 2003, 2004, 2005 and 2006 . Robust SEs are in parentheses. ${ }^{*} 10 \%$, ${ }^{* *} 5 \%,{ }^{* * *} 1 \%$ in a one-tail t-test. See the notes in table 1. 


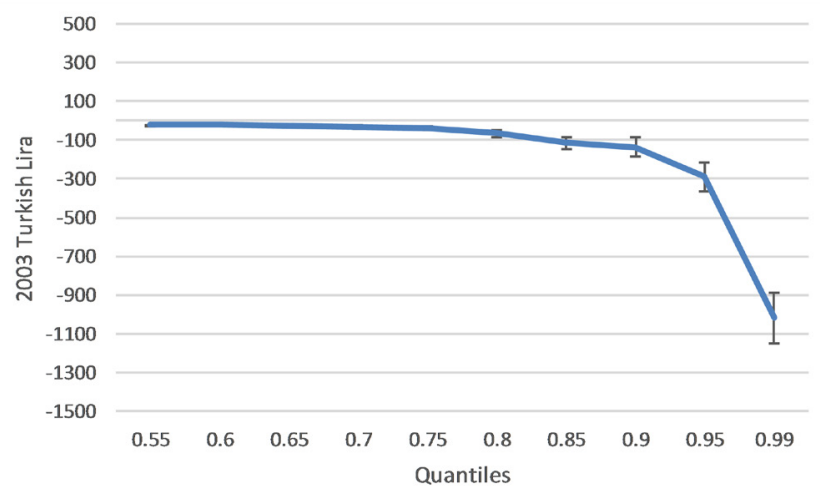

Figure 1 Difference-in-differences estimates of the impact of the benefits expansion on total annualised medical spending at different points in distribution of expenditures (full sample, no covariates). Authors' analysis of Turkey Household Budget Surveys: 2003, 2004, 2005 and 2006. Based on difference-in-differences estimates for total annualised medical spending. We annualised the monthly difference-in-differences estimates. Bars represent 95\% Cls.

except for total household medical spending and pharmaceutical spending, which are statistically significant at $5 \%$ and $10 \%$ level in a one-tailed test, respectively. Table 2 also presents main results of difference-in-differences estimates of the benefits expansion with controls where results are similar to those without controls. We observe a $20 \%$ decline in average yearly out-of-pocket total healthcare expenditures for those with positive health spending and with Green Card health insurance.

\section{Heterogeneous effects by expenditure quantiles}

We found that large expenditures are concentrated in only a few households and savings are much greater in those households. We can begin to get an idea of how important this is by using quantile regression.

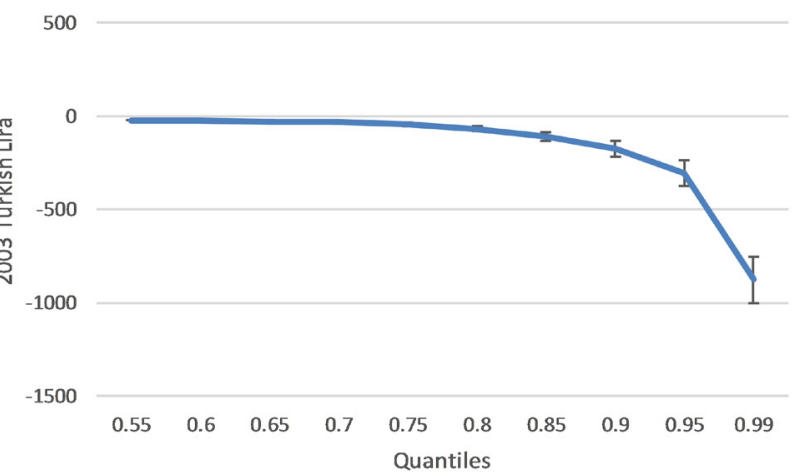

Figure 2 Difference-in-differences estimates of the impact of the benefits expansion on total annualised medical spending at different points in distribution of expenditures (full sample, covariate-adjusted). Authors' analysis of Turkey Household Budget Surveys: 2003, 2004, 2005 and 2006. Based on difference-in-differences estimates for total annualised medical spending. We annualised the monthly difference-in-differences estimates. We use 95\% Cls.
Figures 1 and 2 illustrate regression results for difference-in-differences estimates of the effect of the benefits expansion in insurance coverage at different points in the expense distribution (see also online supplementary appendix table $3 \mathrm{~A}$ for point estimates of the regression results). For both figures to show annual impacts of the insurance coverage expansion, we annualised the monthly difference-in-differences estimates by multiplying them by 12 .

Figure 1 (without covariate adjustment) shows the impact of the Green Card expansion at different points in the distribution of total annualised expenses. Here we can see that reductions in out-of-pocket expenses are almost non-existent below the 75th percentile and highly concentrated in the top $10 \%$ of the expense distribution. Figure 2 (with covariate adjustment) shows that this pattern persists even when controls are added.

\section{Heterogeneous effects by household geographic location}

Table 3 reports the difference-in-differences estimates of treatment effects by household location. The data show that almost $53 \%$ of the Green Card beneficiaries live in urban areas before the insurance coverage expansion (online supplementary appendix table 1A). Nearly all the savings on outpatient services (including doctor visits and dental care) Green Card holders enjoy is concentrated among city dwellers. This is probably because people have better access to healthcare providers in cities. The point estimate for rural Green Card holders shows no significant savings.

The situation is reversed for out-of-pocket pharmaceutical expenses. In rural areas, Green Card holders save 25.00 TL a year (a $36 \%$ savings), while city dwellers see a non-significant small advantage with the new coverage.

\section{Difference-in-differences estimates of incidence of catastrophic healthcare expenditures}

Table 4 presents results for our difference-in-differences analysis of the incidence of catastrophic healthcare expenses. We defined total expenses in excess of $15 \%$, $25 \%$ or $40 \%$ of total expenditures on non-food consumption as catastrophic and look at the impact of the Green Card reform on the frequency of each category. We find that the reform reduced the frequency of catastrophic expenses in those categories by $1.5 \%, 0.8 \%$ and $0.7 \%$ points, respectively. The first and third reductions are statistically significant at the 0.05 level in a one-tailed t-test. When compared the change in the frequency of catastrophic expenses (first row) for Green Card enrollees prior to the reform of $7.7 \%, 3.7 \%$ and $1.5 \%$, our point estimates suggest that the Green Card reform reduced the incidence of catastrophic health expenses by $19 \%, 22 \%$ and $47 \%$ at the three levels, respectively, for Green Card beneficiaries. We estimate these impacts separately for rural and urban Green Card holders. The results are very similar and as a result we could not reject the hypothesis that the reductions were equal for all categories. 
Table 3 Difference-in-differences estimates of heterogeneous treatment impact of benefits expansion in insurance coverage for Green Card on annualised out-of-pocket healthcare expenditures (in Turkish Lira)

\begin{tabular}{|c|c|c|}
\hline \multirow[b]{2}{*}{ Outcome } & \multicolumn{2}{|c|}{ By household geographic location } \\
\hline & Rural & Urban \\
\hline Doctor visit & $1.020(9.420)$ & $-14.064^{\star \star}(7.032)$ \\
\hline Dentist & $6.660(6.372)$ & $-20.316^{\star \star \star}(5.868)$ \\
\hline Diagnostic & $-5.448(4.800)$ & $-7.932(8.004)$ \\
\hline Household pharmaceutical medical spending & $-24.528^{\star \star \star}(10.224)$ & $-1.428(9.624)$ \\
\hline Household total medical expenditures & $-46.716^{\star \star}(27.024)$ & $-70.056^{\star * \star}(22.608)$ \\
\hline \multicolumn{3}{|l|}{ Compare declines above with: } \\
\hline Mean total household medical spending & 192.732 & 205.884 \\
\hline Total decline as per cent of total per-household medical spending & 24 & 34 \\
\hline$X$ variables & Yes & Yes \\
\hline Observations & 18673 & 32752 \\
\hline
\end{tabular}

Authors' analysis of Turkey Household Budget Surveys: 2003, 2004, 2005 and 2006. Robust SEs are in parenthesis. * $10 \%$, * $5 \%$, ${ }^{* *} 1 \%$ in a one-tail t-test. See the notes in table 1.

We study the robustness of our estimates to different combinations of comparison groups and present these in panel 2.

\section{DISCUSSION}

In this study, using difference-in-differences study design, we assess the role of having a Green Card in protecting the poor against financial risks associated with healthcare costs. The results in this paper are consistent with the hypothesis that health insurance protects people from out-of-pocket health spending. We find evidence that Green Card possession provides some protection against financial burden of illness for a variety of outcome measures, specifically dental care, diagnostics, pharmaceutical and total out-of-pocket healthcare expenses. To the best of our knowledge, this is the first study to examine the effects of expansion of health insurance coverage for the poor on their out-of-pocket healthcare expenditures in Turkey.

A goal of every health system is to protect citizens from financial risks of healthcare spending. ${ }^{36}$ Unanticipated healthcare costs lead to financial risks for households in developing countries, especially for the most disadvantaged ones. A significant policy question is whether to increase health insurance coverage to protect poor families from catastrophic health expenditures. Although we have found strong evidence that expanded insurance coverage in Turkey provides risk protection against the cost of illness, this may not always be true in other contexts. In China, due to the light regulation in the healthcare market, providers offer high-tech care to patients and this results in high out-of-pocket health expenses. ${ }^{10}$ Miller et al (2013) assess the impact of Colombia's health insurance programme on various subjects. Turkey's Green Card and Colombia's Régimen Subsidiado health insurance programmes share features in a way that they are both publicly financed, targeted to the poor and intend to reduce the out-of-pocket medical expenditures. In their study, they find that the Colombian programme protected the poor from making large healthcare payments, which is consistent with our findings. Another important study on the effect of health insurance on financial protection by Sepehri et al indicates that non-profit health insurance reduces financial

Table 4 Difference-in-differences estimates of the impact of benefits expansion in insurance coverage for Green Card on the incidence of catastrophic healthcare expenditures (full sample, in Turkish Lira)

\begin{tabular}{llll}
\hline & & \multicolumn{2}{l}{$\begin{array}{l}\text { Incidence of catastrophic health } \\
\text { expenditures }\end{array}$} \\
\cline { 2 - 4 } Outcome/threshold & $\mathbf{1 5 \%}$ & $\mathbf{2 5 \%}$ & $\mathbf{4 0 \%}$ \\
\hline Change in households experiencing catastrophic costs (\%) & $-1.5^{\star *}(0.9)$ & $-0.8(0.7)$ & $-0.7^{* *}(0.4)$ \\
Frequency of catastrophic expenses prior to the Green Card reform (\%) & 7.7 & 3.7 & 1.5 \\
Decline in the incidence of catastrophic health expenses (\%) & 19 & 22 & 47 \\
X variables & & 51425 \\
\hline Observations & & Yes \\
\hline
\end{tabular}

Authors' analysis of Turkey Household Budget Surveys: 2003, 2004, 2005 and 2006 . Robust SEs are in parenthesis. ${ }^{*} 10 \%$, ${ }^{* *} 5 \%$, ${ }^{* *} 1 \%$ in a one-tail test. See the notes in table 1. 
Panel 2: robustness/sensitivity analysis: various combinations of comparison groups

Our comparison group in the analysis above consists of people covered by three different insurance programmes: social insurance, uninsured and private insurance (includes other insurances). Our first robustness test is to include dummy variables for each of the insurance type. This does not change the statistical or quantitative significance of the impact of the coverage change for Green Cards.

Next, we 'remove' each of the insurance types in the comparison group one by one by treating it as a separate treatment group (we add a dummy for the type of insurance as well as the interaction of that dummy with the postchange variable). We do this first for the uninsured (keeping privately insured and those with social insurance in the comparison group). The results are substantively unchanged (online supplementary appendix table 4A) as they are when we take each of the other two insurance types out of the comparison group in turn (online supplementary appendix tables $5 \mathrm{~A}$ and $6 \mathrm{~A})$.

The last robustness check compares Green Card holders only to the uninsured. One might think that people without any health insurance are the most suitable comparison group as they are a low-income group as are the Green Card holders. Therefore, in this robustness analysis, we compare out-of-pocket healthcare expenditures of those with Green Card insurance with that of those with no health insurance before and after the policy change. Per online supplementary appendix table 7A, the estimated impact of the Green Card reform is nearly unchanged compared with the estimate with the full set of controls.

The primary results are strikingly robust to the composition of the comparison group. There is further evidence that the difference-in-differences estimates satisfy the parallel trend assumptions and that the effects we estimate are causal.

If it is the policy change in 2005 that is producing the statistically significant reductions in expenditures that we are seeing, then the model should fit best when we choose the beginning of 2005 as our break point. We tried 'placebo' breaks in the previous year and the year after the law went into effect. The $\mathrm{R}^{2}$ was highest when the break was set at the point of the change in policy suggesting that if there is a change that is the year it took place in. ${ }^{35}$

We also execute another placebo test that looks at out-of-pocket healthcare spending on inpatient care services, which were previously covered by the insurance. As it was covered before, we did not expect to see the spending pattern changing related to this type of health expenditure. As one would expect if the Green Card expansion were the cause of the change we see no impact on this category of expenditures which was covered before the expansion.

burden more for lower income individuals in Vietnam. Findings of this study are also consistent with our results for Turkey, suggesting that insurance protects the poor or underprivileged against making large out-of-pocket health payments.

Earlier studies have investigated the effects of health insurance on out-of-pocket healthcare expenditures in Turkey. One recent study shows that ratio of households with non-zero out-of-pocket health expenditures has increased for premium-based public insurees, whereas share and level of health expenditures have decreased. ${ }^{24}$ Another study indicates that the rapid roll-out and successful targeting of the Green Card insurance programme has helped to increase the insurance coverage for the poor people in Turkey while it helped to reduce out-of-pocket health expenditures slightly. ${ }^{22}$ Our results, which use difference-in-differences study design, considering self-selection of individuals into the Green Card scheme during the coverage expansion period, produce convincing and large estimates supporting the hypothesis that health insurance protects people from the cost of illness.

There might be situations where people with unobserved characteristics may tend to opt for health insurance. This will bias the coefficients on insurance in the estimating equation for the out-of-pocket healthcare expenditures. Taking the aforementioned scenarios into account, which were highlighted in the Data and Sample section, if anything, it will lead us to the underestimation of out-of-pocket health expenditures that Green Card causes. In addition, to justify the use of difference-in-differences study design, we test the parallel trend assumption that the healthcare expenditure patterns for both the treated and the comparison groups would be the same in the absence of treatment, which we fail to reject.

Another limitation of our study is that our data consist of cross-sectional household surveys and we do not have panel data that would allow us to watch the same households' health expenditures over the years. However, difference-in-differences method is widely used in the literature when one has to work with cross-sectional surveys. ${ }^{27}$ Moreover, unfortunately, we do not have regional or geographic identifiers in the datasets to control for regional fixed effects to account for geographic differences in our analysis.

Notwithstanding limitations, the most imperative finding of this study is to reflect on the most vulnerable group's out-of-pocket healthcare expenditures who are in the upper tail of the health spending distribution. We find that reductions in out-of-pocket healthcare spending for low-income households are considerably larger near the top of the distribution. This evidence is important in the sense that those who need the insurance the most will be the ones who benefit from the insurance coverage expansion more by being protected from the financial catastrophe.

Turkey's success in implementing large-scale health system changes to benefit the poor offers five major lessons for countries introducing similar schemes. First, health system reforms in Turkey including demandside (eg, expanded benefits, reduced cost sharing and increased insurance coverage) and supply-side measures (eg, increased human resources and expansion of infrastructure), especially for poor citizens. Similarly, Thailand gradually extended health insurance coverage and benefits package while strengthening primary healthcare. ${ }^{37}$ 
Second, implementing a hybrid system combining local knowledge with criteria determined by the central government enabled rapid roll-out of the Green Card scheme. In 2003, in the poorest decile just $25 \%$ of the individuals were covered by any kind of insurance, but by 2006 coverage in this group had increased to $68 \%$ (of which $54 \%$ Green Card enrollees). ${ }^{22}$

Third, a comprehensive transformation strategy, political stability and commitment by leadership among were important drivers of the change in Turkey's health system benefiting the poorest by reducing their out-of-pocket health expenditures. Economic growth in 2003-2013 created the fiscal space for the government to invest in health.

Fourth, expanding insurance coverage for the poor in Turkey and unifying benefits for various insurance schemes provided financial protection for the poor. In most of the low-income and middle-income countries, out-of-pocket health expenditures are high. ${ }^{38}$ Expansion of Green Card scheme enabled reduction of out-of-pocket health expenditures in Turkey. Globally, there is a strong debate whether expansion of UHC provides financial protection for the poor through risk pooling mechanism to pay for health. ${ }^{39}$ In Ghana, the national health insurance programme reduced out-of-pocket payments greatly and protected households from poverty. ${ }^{38}$ In Bangladesh, there are calls to introduce UHC to provide financial risk protection and reduce out-of-pocket payments to alleviate poverty. ${ }^{40}$

Fifth, establishment of field coordinator consisted of a team of physicians, who regularly visited reform implementation sites across the country for local assessment, problem solving and lesson learning was also an important in rapid problem solving to accelerate implementation.

Our findings suggest that non-contributory government-funded health insurance programme for the poor, such as Turkey's Green Card scheme, could significantly reduce out-of-pocket healthcare expenditures. Expanding insurance coverage helps the poor to bear the costs of medical care and save more, so that they can use these savings wherever they need them most. As some of the biggest savings are realised in urban areas, our findings are particularly relevant for countries with growing urban populations. However, we also show that large reductions in the frequency of catastrophic expenses are observed in both rural and urban areas. Turkey's experience is noteworthy for low-income and middle-income countries, which intend to introduce health reforms targeting low-income groups.

Contributors RA and AT conceived the study. AT undertook the analysis with guidance from RA and WTD. RA and WTD contributed to analysis of the results. AT wrote the first draft with guidance and input from RA. AT and RA revised the manuscript. All authors provided input to the final draft and have approved it.

Funding The authors have not declared a specific grant for this research from any funding agency in the public, commercial or not-for-profit sectors.

Competing interests None declared.

Patient consent for publication Not required.
Provenance and peer review Not commissioned; externally peer reviewed.

Data availability statement Data may be obtained from a third party and are not publicly available.

Open access This is an open access article distributed in accordance with the Creative Commons Attribution Non Commercial (CC BY-NC 4.0) license, which permits others to distribute, remix, adapt, build upon this work non-commercially, and license their derivative works on different terms, provided the original work is properly cited, appropriate credit is given, any changes made indicated, and the use is non-commercial. See: http://creativecommons.org/licenses/by-nc/4.0/.

\section{REFERENCES}

1. World Health Organization. The World Health Report 2000: health systems: improving performance. World Health Organization, 2000.

2. Xu K, Evans DB, Carrin G, et al. Protecting households from catastrophic health spending. Health Aff 2007;26:972-83.

3. Poverty FJ. Out-Of-Pocket payments and access to health care: evidence from Tajikistan. Social Science \& Medicine 2004:58:247-58.

4. Escobar M-L, Griffin CC, Shaw RP. The impact of health insurance in low-and middle-income countries. Brookings Institution Press, 2011.

5. Finkelstein A, McKnight R. What did Medicare do? The initial impact of Medicare on mortality and out of pocket medical spending. $J$ Public Econ 2008;92:1644-68.

6. J-FR L, Hsiao WC. Does universal health insurance make health care unaffordable? lessons from Taiwan. Health affairs 2003;22:77-88.

7. Miller G, Pinto D, Vera-Hernández M. Risk protection, service use, and health outcomes under Colombia's health insurance program for the poor. Am Econ J Appl Econ 2013;5:61-91.

8. Somkotra T, Lagrada LP. Payments for health care and its effect on catastrophe and impoverishment: experience from the transition to universal coverage in Thailand. Soc Sci Med 2008;67:2027-35.

9. Sepehri A, Sarma S, Simpson W. Does non-profit health insurance reduce financial burden? Evidence from the Vietnam living standards survey panel. Health Econ 2006;15:603-16.

10. Wagstaff A, Lindelow M. Can insurance increase financial risk? the curious case of health insurance in China. $J$ Health Econ 2008;27:990-1005

11. Gertler P, Solon O. Who benefits from social health insurance in developing countries? Draft UC Berkeley, 2000.

12. Rubin RM, Koelln K. Determinants of household out-of-pocket health expenditures. Social science quarterly 1993;74:721-35.

13. Shen Y-C, McFeeters J. Out-Of-Pocket health spending between low-and higher-income populations: who is at risk of having high expenses and high burdens? Medical Care 2006;44:200-9.

14. Waters HR, Anderson GF, Mays J. Measuring financial protection in health in the United States. Health Policy 2004;69:339-49.

15. Van Minh H, Kim Phuong NT, Saksena P, et al. Financial burden of household out-of pocket health expenditure in Viet Nam: Findings from the National Living Standard Survey 2002-2010. Soc Sci Med 2013;96:258-63.

16. Feldstein MS. The welfare loss of excess health insurance. J Polit Econ 1973;81:251-80.

17. Atun R, Aydın S, Chakraborty S, et al. Universal health coverage in Turkey: enhancement of equity. The Lancet 2013;382:65-99.

18. Berman P, Tatar M. Turkey National health accounts 1999-2000. Ankara: Ministry of Health, 2004.

19. Tatar M, Özgen H, Sahin B, et al. Informal payments in the health sector: a case study from Turkey. Health Aff 2007;26:1029-39.

20. Bank OTW. OECD reviews of health systems. Turkey: OECD Publishing, 2008.

21. Menon R, Mollahaliloglu S, Postolovska I. Toward Universal Coverage: Turkey's Green Card Program for the Poor 2013.

22. Aran MA, Hentschel J. Protection in good and bad times? the Turkish green card health program. The Turkish green card health program (August 1, 2012) world bank policy research working paper 2012;(6178).

23. Sulku SN, Bernard DM. Financial burden of health care expenditures: Turkey. Iran J Public Health 2012;41:48-64.

24. Erus B, Aktakke N. Impact of healthcare reforms on out-of-pocket health expenditures in turkey for public insurees. Eur $\mathrm{J}$ Health Econ 2012;13:337-46.

25. Yardim MS, Cilingiroglu N, Yardim N. Catastrophic health expenditure and impoverishment in Turkey. Health Policy 2010;94:26-33.

26. Institute TS. Turkey household budget survey. in: Institute Ts, editor Ankara; 2003, 2004, 2005. Ankara: Institute TS, 2006. 
27. Gruber J, Hendren N, Townsend RM. The great equalizer: health care access and infant mortality in Thailand. Am Econ J Appl Econ 2014;6:91-107.

28. Meyer BD. Natural and quasi-experiments in economics. JBES 1995;13:151-61.

29. Muralidharan K, Prakash N. Cycling to school: increasing secondary school enrollment for girls in India: national Bureau of economic research 2013.

30. Cade BS, Noon BR. A gentle introduction to quantile regression for ecologists. Front Ecol Environ 2003;1:412-20.

31. Wagstaff A, Doorslaer Evan, Ev D. Catastrophe and impoverishment in paying for health care: with applications to Vietnam 1993-1998. Health Econ 2003;12:921-33.

32. Xu K, Evans DB, Kawabata K, et al. Household catastrophic health expenditure: a multicountry analysis. The Lancet 2003:362:111-7.

33. Berki SE. A look at catastrophic medical expenses and the poor. Health Aff 1986;5:138-45.

34. Wagstaff A, O'Donnell O, Van Doorslaer E, et al. Analyzing health equity using household survey data: a guide to techniques and their implementation. World Bank Publications, 2007.
35. Bhattacharya P. Some aspects of change-point analysis. Lecture Notes-Monograph series 1994:28-56.

36. Ellis RP, McGuire TG. Supply-Side and demand-side cost sharing in health care. J Econ Perspect 1993;7:135-51.

37. Tangcharoensathien V, Pitayarangsarit S, Patcharanarumol W, et al. Promoting universal financial protection: how the Thai universal coverage scheme was designed to ensure equity. Health Res Policy Syst 2013;11.

38. Aryeetey GC, Westeneng J, Spaan E, et al. Can health insurance protect against out-of-pocket and catastrophic expenditures and also support poverty reduction? Evidence from Ghana's National health insurance scheme. Int J Equity Health 2016;15:116.

39. Mulenga A, Ataguba JE-O. Assessing income redistributive effect of health financing in Zambia. Soc Sci Med 2017;189:1-10.

40. Khan JAM, Ahmed S, Evans TG. Catastrophic healthcare expenditure and poverty related to out-of-pocket payments for healthcare in Bangladesh-an estimation of financial risk protection of universal health coverage. Health Policy Plan 2017;32:1102-10. 